\title{
Strength Test and Modal Analysis for a Standardized High-Speed EMU Motor Bogie Frame
}

\author{
Yongyang Zhang ${ }^{1, \mathrm{a}^{*}}$, Pingbo $\mathrm{Wu}^{2}$, Ye Song ${ }^{3}$ \\ Full address of author: State Key Laboratory of Traction Power, Southwest Jiaotong University, \\ Chengdu, Sichuan, China \\ aemail: zyyang0509@163.com
}

Keywords: bogie frame, strength test, fatigue strength, modal analysis

Abstract. Bogie frame is the critical components of high-speed electric multiple units (EMU). In this article, the static strength test and fatigue strength test of a standardized high-speed EMU motor bogie frame were conducted. According to the strength test results, the static strength and fatigue strength of the frame was checked referring to UIC615- 4 and Goodman sketch for welding materials. The modal analysis of the frame to evaluate the dynamical behavior of the frame in order to meet the dynamical design requirements. Analyzed with the simulation results, the static strength and fatigue strength of the bogie frame can meet the requirements. The lower self-vibration frequency of the frame is $47.96 \mathrm{HZ}$ which can avoid excited frequency of the frame.

\section{Introduction}

Chinese high-speed EMU, according to "the introduction of advanced technology, the joint design and production, to build China brand" requirement ${ }^{[1]}$, through the introduction of absorption and innovation, has produced a completely independent intellectual property rights, the world's advanced level of high-speed EMU. In order to independence, standardize and serialize the high-speed train, now carried on EMU system type. Bogie frame is the critical components of high-speed EMU, Its reliability directly affect the safe operation of the vehicle, and its vibration will affect the stability and safety of the vehicle ${ }^{[2]}$. Bogie frame is an important component parts bogie suspension means, shock absorber, etc. Will also vehicle body mass and vibration is transmitted to the wheel, at the same time withstand the load of the parts on the frame produced during operation ${ }^{[3]}$. Due to the importance of bogie frame, before the new standardized high-speed EMU put into operation to test its strength, to ensure the safe operation of trains has very important significance.

In this thesis, the strength test of the bogie frame of a standard EMU according to test basis UIC 615-4 ${ }^{[4]}$ and EN $13749^{[5]}$. According to the stress obtained in service load cases, the Goodman diagram is used to evaluate whether the stress of casting exceeds the fatigue limit, and assessment of fatigue strength under a certain number of cycles of fatigue testing. Through the strength test and modal analysis to find the weak parts of the bogie frame, and provide the basis for structure optimization.

\section{Strength test program}

The hydraulic servo system which consists of the hydraulic pressure station, servo vibrating controller and 50t, 25t and 5t vibration exciters is imported from MTS. This system satisfies requirements of static strength test and the fatigue test under different static loads. Data acquisition system using DH3821 static strain gauge, DH3821 produced by Jiangsu Donghua test technology Co.,Ltd.

Strength tests were arranged 8 vibration exciters, vertical and horizontal air springs each two vibration exciters, one vibration exciters at lateral stop, two roll vibration exciters. During the test frame through axle box boom and two false-axis linking, false-axis fixed three directions, each support includes two mutually perpendicular ball joint to ensure a certain degree of freedom in the bogie frame, so it can better simulate actual bogie frame of the forces ${ }^{[6]}$.The bogie frame in strength test bench as shown in Fig.1, Two mutually perpendicular ball joint as shown in Fig.2. 


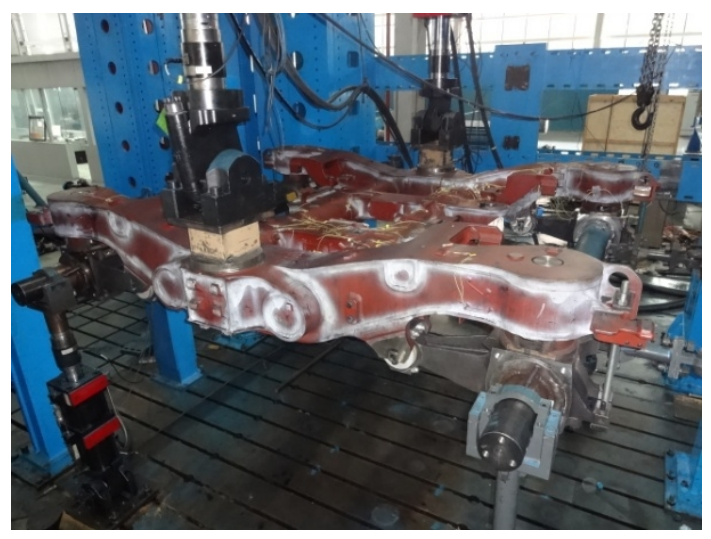

Fig.1 The bogie frame in test bench

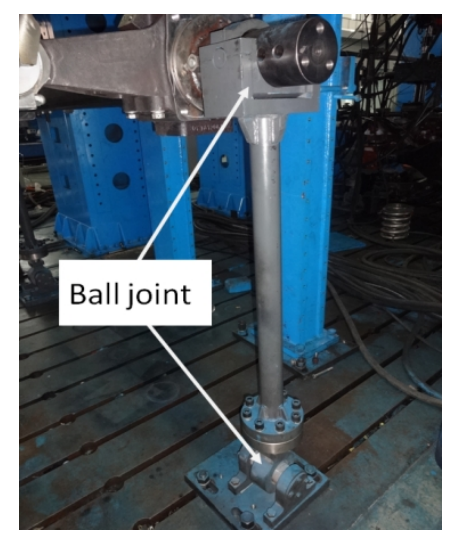

Fig.2 Two mutually perpendicular ball joint

Strain gauges and strain rosettes are attached to the bogie frame at all highly stressed points, in particular in zones of stress concentration. The estimated number of the strain gauges for the frame is 138 consisting of 128 one direction strain gauge and 10 three direction strain gauge. The length of the one direction strain gauge is $6 \mathrm{~mm}$, while that of the three direction stain gauge is $3 \mathrm{~mm}$. When measuring points are arranged to consider the multiple sets of symmetrical and skew-symmetric measuring point for subsequent analysis of data provided convenience ${ }^{[7]}$.

\section{The Strength Test Load Cases}

The strength test load diagram as shown in fig. 3 .

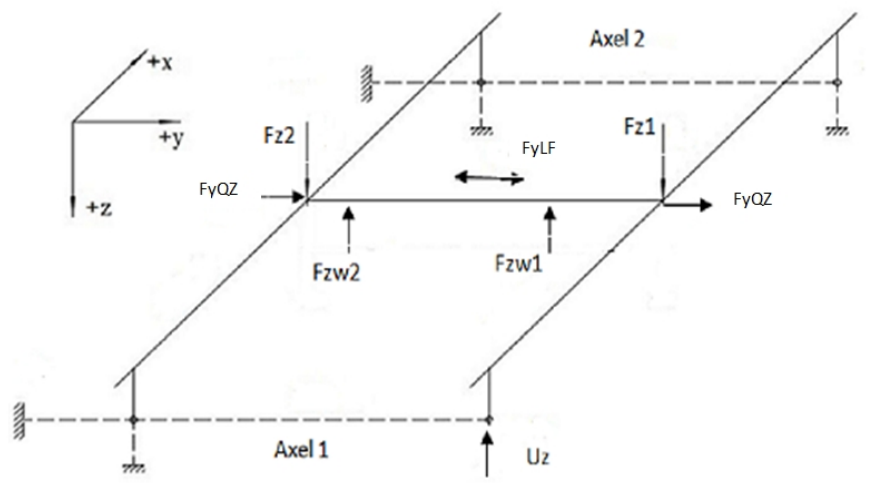

Fig. 3 The strength test load diagram

Static Test Load of the Bogie Frame. According to The bogie frame parameters, reference UIC615-4, EN 13749 standards. Vertical load $F z$ of per air spring seat can be calculated.

$\mathrm{Fz}=\mathrm{g} / 4\left(\mathrm{~m}_{\mathrm{v}}+\mathrm{c}_{1}-2 \mathrm{~m}\right)=135.87 \mathrm{kN}$

Where, $m_{v}+c_{1}$ full axle load calculation in accordance with, $m$ bogie mass, $g$ is the gravitational acceleration. Exception loads acting on the air spring seat vertical load $1.4 F z$.

Lateral force $F y$ with Exception loads can be calculated according to the following formula.

$\mathrm{Fy}=2\left(10^{4}+\left(\mathrm{m}_{\mathrm{v}}+\mathrm{c}_{1}\right) / 12 \times \mathrm{g}\right)=123 \mathrm{kN}$

Lateral force $F^{\prime} y$ with service loads.

$\mathrm{F}^{\prime} \mathrm{y}=0.5(\mathrm{Fz}+0.5 \mathrm{mg})=75.2 \mathrm{kN}$

Lateral load include lateral force secondary air spring and lateral force at lateral stop.Lateral force allocation, lateral force secondary air spring $F y Q Z=8.2 \mathrm{kN}$.

Factors $\alpha$ and $\beta$, which are expressed as a percentage of the average vertical force, are usually used to define the dynamic vibration due to the side roll and ups and downs of the vehicle body. According to UIC615-4, EN13749 under the condition of a normal operating railroad, $\alpha=0.1, \beta=0.2$. Vertical force per anti-roll bar link $54.3 \mathrm{KN}$, with exception loads, $34.53 \mathrm{kN}$ with exception loads.

Bogie wheelbase is $2500 \mathrm{~mm}$, when crossing the transition curve whose longitudinal rate is $10 \%$ o with exception loads, longitudinal rate is $5 \%$ with service loads, the skew symmetric deformation of the frame can be achieved by making part of the frame form a vertical displacement. 
Select some typical working conditions, the exceptional load cases combination are shown in table1, the service load cases combinations are shown in table2. The steps of how the load are applied: we apply $50 \%$ full load to the bogie before the full load is applied and forecast whether the stress will exceed the yield limit when the full load is applied base on the stress we get when $50 \%$ of full load is applied, if the stress we predict exceeds the yield limit, the test shall be suspended.

Table 1 Static tests with exception loads

\begin{tabular}{|c|c|c|c|c|c|c|}
\hline Load case & Fz1/KN & Fz2/KN & FyLF/KN & FyQZ/ KN & FzW 1/KN & Uz/ mm \\
\hline NO. & Per air spring & Per air spring & Per Bogie & Per air spring & -FZW2/KN & One wheel \\
\hline E01 & 190.2 & 190.2 & & & & \\
\hline E02 & 190.2 & 190.2 & 114.8 & 8.2 & & \\
\hline E03 & 190.2 & 190.2 & -114.8 & -8.2 & & \\
\hline E04 & 190.2 & 190.2 & & & & 25 \\
\hline E05 & 190.2 & 190.2 & & & & -25 \\
\hline E06 & 190.2 & 190.2 & 114.8 & 8.2 & & 25 \\
\hline E07 & 190.2 & 190.2 & 114.8 & 8.2 & & -25 \\
\hline E08 & 190.2 & 190.2 & -114.8 & -8.2 & & 25 \\
\hline E09 & 190.2 & 190.2 & -114.8 & -8.2 & & -25 \\
\hline E10 & 218.4 & 107.7 & 114.8 & 8.2 & 54.3 & \\
\hline E11 & 107.7 & 218.4 & -114.8 & -8.2 & -54.3 & \\
\hline
\end{tabular}

Table 2 Static tests with main in service loads

\begin{tabular}{|c|c|c|c|c|c|c|}
\hline Load case & Fz1/KN & Fz2/KN & FyLF/KN & FyQZ/KN & FzW1 / KN & Uz/mm \\
\hline NO. & Per air spring & Per air spring & Per Bogie & Per air spring & -FZW2 / KN & One wheel \\
\hline MIS01 & 135.87 & 135.87 & & & & \\
\hline MIS02 & 176.63 & 149.46 & & & & \\
\hline MIS03 & 176.63 & 149.46 & 67 & 8.2 & & \\
\hline MIS04 & 149.46 & 176.63 & & & & \\
\hline MIS05 & 149.46 & 176.63 & -67 & -8.2 & & \\
\hline MIS06 & 176.63 & 149.46 & 67 & 8.2 & & 12.5 \\
\hline MIS07 & 149.46 & 176.63 & -67 & -8.2 & & 12.5 \\
\hline MIS08 & 176.63 & 149.46 & 67 & 8.2 & & -12.5 \\
\hline MIS09 & 149.46 & 176.63 & -67 & -8.2 & & -12.5 \\
\hline MIS10 & 198.23 & 127.85 & 67 & 8.2 & 34.53 & \\
\hline MIS11 & 143.89 & 73.5 & 67 & 8.2 & 34.53 & \\
\hline MIS12 & 127.85 & 198.23 & -67 & -8.2 & -34.53 & \\
\hline MIS13 & 73.5 & 143.89 & -67 & -8.2 & -34.53 & \\
\hline
\end{tabular}

Fatigue Test Load of the Bogie Frame. Apply fatigue load according to UIC615-4, the cyclic times of the bogie frame dynamic fatigue test is 10 million. The main fatigue test of the frame has 3 levels including 6 millions, 2 millions and 2 millions loading cycles. The bogie is inspected by magnetic particle inspection after each fatigue test. Fatigue test loads are shown in table 3 .

Table 3 Fatigue test loads

\begin{tabular}{|c|c|c|c|c|c|c|c|}
\hline \multirow{2}{*}{ Component } & \multicolumn{3}{|c|}{ Load } & \multirow{2}{*}{ Uint } & \multicolumn{3}{|c|}{ Loads for fatigue phase } \\
\hline & Direction & Type & Note & & 1 load & 2 load & 3 load \\
\hline \multirow{6}{*}{ Air spring } & \multirow{4}{*}{ Vertical } & stat & $\mathrm{Fzl}=\mathrm{Fz2}$ & $\mathrm{kN}$ & 125.52 & 125.52 & 125.52 \\
\hline & & quasi stat & $\mathrm{Fzl}=\mathrm{Fz2}$ & kN & 17.6 & 21.11 & 24.63 \\
\hline & & dyn bounce & $\mathrm{Fzl}=\mathrm{Fz2}$ & $\mathrm{kN}$ & 25.1 & 30.12 & 35.15 \\
\hline & & dyn roll & $\mathrm{Fz1}=\mathrm{Fz2}$ & $\mathrm{kN}$ & 17.6 & 21.11 & 24.63 \\
\hline & \multirow{2}{*}{ Lateral } & quasi stat & Fy1=Fy2 & $\mathrm{kN}$ & 4.1 & 4.91 & 5.73 \\
\hline & & dyn & Fy1=Fy2 & $\mathrm{kN}$ & 4.1 & 4.91 & 5.73 \\
\hline \multirow{2}{*}{ Lateral bumpstop } & \multirow{2}{*}{ Lateral } & quasi stat & FyQZ1 or -FyQZ1 & $\mathrm{kN}$ & 33.5 & 40.2 & 46.9 \\
\hline & & dyn & FyQZ1 or FyQZ1 & $\mathrm{kN}$ & 33.5 & 40.2 & 46.9 \\
\hline \multirow{2}{*}{ Anti Roll Bar } & \multirow{2}{*}{ Vertical } & quasi stat & Fzw 1=-Fzw2 & $\mathrm{kN}$ & 17.27 & 20.72 & 24.17 \\
\hline & & dyn & Fzw1=Fzw2 & $\mathrm{kN}$ & 17.27 & 20.72 & 24.17 \\
\hline Twist (wheel ) & Vertical & dyn & one wheel & $\mathrm{mm}$ & 12.5 & 15 & 17.5 \\
\hline
\end{tabular}




\section{Strength Test Results of the Bogie Frames}

Static Strength Test Results. The welded frame subjects, mainly by the steel plate and seamless steel tubes welded together, the material used for the beam SMA490BW seamless steel tubes, side sill box-type welded structure by the steel plate S355J2W material.

The max stress under exceptional load is $146.9 \mathrm{MPa}$, at side sill and beam joint inside, it's tensile stress doesn't exceed the allowable stress $355 \mathrm{MPa}$, therefore there will not be residual stress. The max stress under service loads is $115.6 \mathrm{MPa}$, at side sill and beam joint inside, it's tensile stress doesn't exceed the allowable stress $305 \mathrm{MPa}$. The static strength of the bogie frame can meet the requirement.

Fatigue Assessment. According to the test results, the fatigue strength of the frame is checked refer ring to UIC615-4 and Goodman sketch for welding materials, as shown in Fig.4. It can be seen from Fig.4, the static strength test results based on the service load can meet the requirement. The bogie frame is inspected by magnetic particle inspection method when the fatigue cycle is 6 million, 8 million and 10 million, no crack was found by magnetic particle inspection. The fatigue strength can meet the requirement.

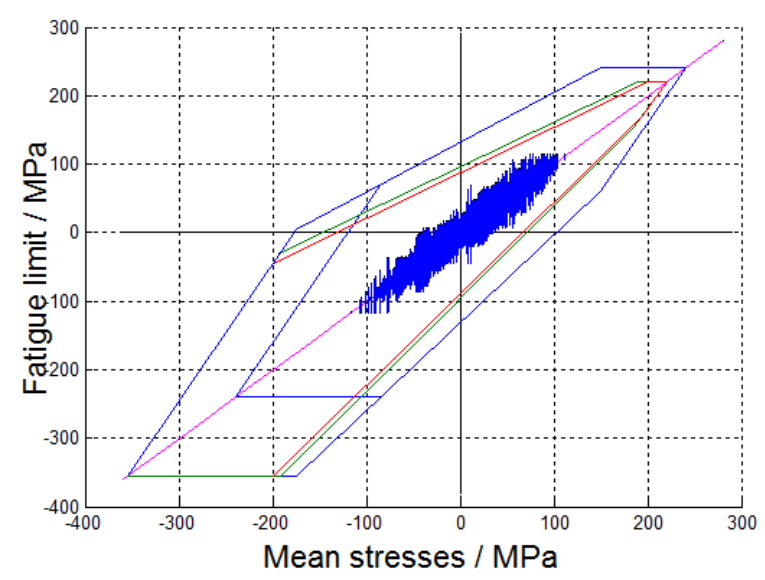

Fig.4 he Goodman fatigue assessment curves

\section{Modal Analysis}

Modal analysis is to identify the modal parameters of the system, providing the basis of structure vibration characteristic analysis, the vibration fault diagnosis and forecast, and the dynamic characteristics of the structure optimization design. The modal analysis is calculated using ANSYS software, the accuracy of the simulation mesh is directly related to the accuracy of the finite element calculation. The meshing seeks to be close to the original structure and the combination of thin and thick style is adopted to mesh the grid. The frame is discrete into 372196 nodes and 1270598 elements which can be seen in fig.5. Due to train in the use of the process is generally not a high-frequency vibration, this report calculate the frame before 6 order modal frequency and modal shape, Specific modal information can be seen in table 4 , and the first modal shape can be seen in fig. 6 .

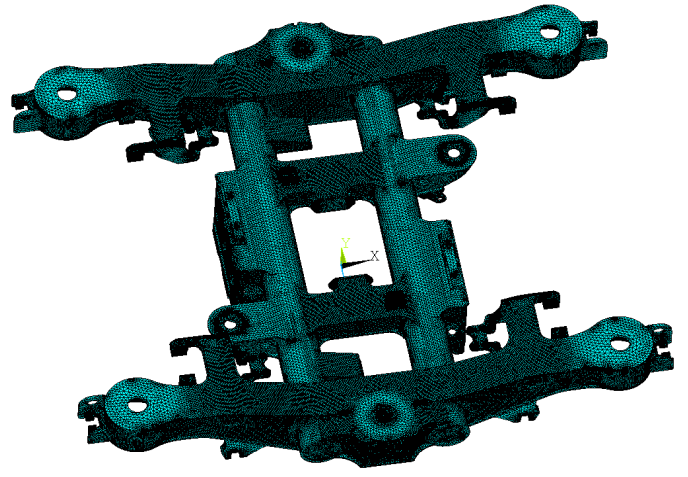

Fig.5 The finite element model of frame

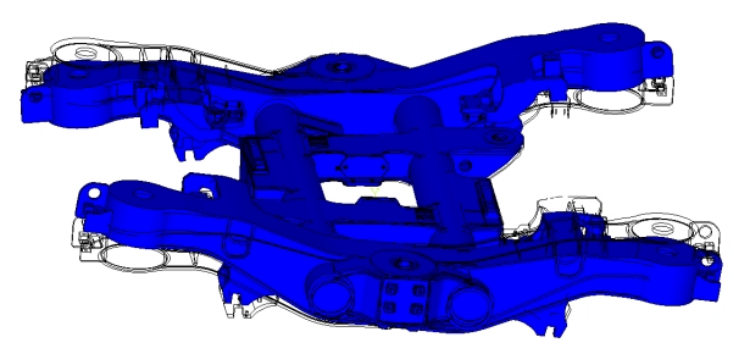

Fig.6 The first order vibration modal shape 
Table 4 Modal analysis results of frame

\begin{tabular}{ccc}
\hline Order & Frequency $(\mathrm{Hz})$ & Mode of vibration \\
\hline 1 & 47.96 & Side sill reverse torsion around beam \\
2 & 90.82 & Side sill bent inward in the horizontal plane \\
3 & 91.93 & Side sill reverse swing in the horizontal plane \\
4 & 99.21 & Side sill syntropy swing in the horizontal plane \\
5 & 121.85 & Frame lateral bending first order \\
6 & 127.86 & Side sill bent outward in the horizontal plane \\
\hline
\end{tabular}

As apparent from Table 4, the first order vibration modal is side sill reverse torsion around beam, this shows that the torsional stiffness of the frame is relatively small, in favor of the bogie by vertical railway Irregularity ${ }^{[8]}$. The fifth order vibration modal is frame lateral bending first order, it show that frame transverse stiffness is bigger, this conducive frame to withstand lateral load. The lower self-vibration frequency of the frame is $47.96 \mathrm{HZ}$ which can avoid excited frequency of the frame.

\section{Conclusions}

Based on the bogie frame strength test data analysis and modal analysis, the following conclusions.

In the static load case test, the max stresses under exceptional load case and service load case are smaller than the limits. The static strength can meet the requirements.

Based on the test results of static strength, the fatigue strength is assessed, the stresses of all tested points are within the Goodman enveloping line which means. The cyclic times of the fatigue test is 10 million, by magnetic particle inspection, no crack was found. The fatigue strength can meet the requirement.

Finite element software Modal analysis showed that: the frame torsional stiffness is relatively small, in favor of the bogie by vertical railway Irregularity. The lower self-vibration frequency of the frame is $47.96 \mathrm{HZ}$ which can avoid excited frequency of the frame.

\section{References}

[1] Chenggu Liang, Explore the Chinese high-speed rail development model [J]. Chinese Railways,2008,09:1-6. (In Chinese)

[2] Boming Wang. High-speed EMU totality and bogie[M].Chengdu: Southwest Jiaotong University Press.2008. (In Chinese)

[3] Juanmao Yan. Vehicle Engineering [M].Beijing: China Railway Publishing House,2005. （In Chinese )

[4] UIC 615-4:2003, Motive power units Bogies and running gear Bogie frame strength tests[S].

[5] EN13749: 2011, Railway applications-Wheel sets and Bogies-Methods of specifying structural requirements of bogie frames [S].

[6] Yingxiong ZHOU, Yong WANG, Ye SONG. Study on static strength test and simulation for high-speed EMU motor bogie frame[J], Machinery, 2014,07:1-5. (In Chinese )

[7] Degang LIU, et al.Comparison of strength test standards for bogie frames[J], Rolling Stock, 2011, 49 (9) : 12-16. (In Chinese)

[8]Yinhua LIU, et al. The satigue strength and modal analysis of bogie frames for freight cars with variable gauges [J], Rolling Stock, 2007，45（11）,1-4.（In Chinese） 